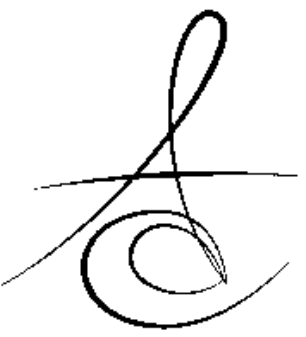

\title{
DİŞETİ İLTİHAPLI VE PERİODONTAL SAĞLIKLI BİREYLERDE TÜKÜRÜK KORTİZOL VE ALGILANAN STRES DÜZEYLERİNİN DEĞERLENDİRİLMESİ
}

\author{
EVALUATION OF SALIVARY CORTISOL LEVELS AND PERCEIVED STRESS \\ LEVELS IN GINGIVITIS AND PERIODONTAL HEALTHY INDIVIDUALS
}

Dr. Öğr. Üyesi Özge GÖKTÜRK* Dr. Öğr. Üyesi Fatma UÇAN YARKAÇ**

Arş. Gör. Ferhat ÖZELÇí⿱艹

Makale Kodu/Article code: 3848

Makale Gönderilme tarihi: 10.10 .2018

Kabul Tarihi: 31.01.2019

\section{öz}

Amaç: Psikososyal faktörler periodontal hastalık için önemli bir risk faktörü olarak tanımlanır, konak direncini değiştirerek ve endokrin dengesizliklere neden olarak periodontal dokuları etkileyebilir. $\mathrm{Bu}$ çalışmada algılanan stres ve strese bağlı hormon düzeyiyle periodontal durum arasındaki ilişkinin değerlendirilmesi amaçlanmıştır.

Gereç ve Yöntem: Bu çalışmaya 42 gingivitisli ve 30 periodontal olarak sağıklı, toplam 72 birey dahil edildi. Hastaların klinik ve radyolojik periodontal değerlendirmesi yapıldı. Stres düzeyleri tükürük kortizol seviyesi ve Cohen Algılanan Stres Ölçeği (ASÖ-10) değerleri kullanılarak incelendi. Bireylerin tükürükteki kortizol seviyesi ELİSA yöntemi kullanılarak ölçüldü. Elde edilen veriler $\mathrm{p}<0.05$ anlamlılık düzeylerine göre istatistiksel olarak analiz edildi.

Bulgular: Sosyodemografik veriler değerlendirildiğinde fırçalama sıklığının kontrol grubunda daha yüksek olduğu görüldü $(p<0.05)$. Periodontal olarak sağlıklı gruptaki tükürük kortizol seviyesi ve ASÖ-10 skorları, gingivitis grubuna kıyasla daha düşüktü $(p<0.05)$. Tükürük kortizol seviyesi ve algılanan stres ölçeği skorları ile periodontal klinik parametreler arasında pozitif korelasyon gözlendi.

Sonuç: Gingivitisli bireylerde daha yüksek stres seviyesi görülmektedir. Çalışmamızın sonuçları dahilinde stres ile periodontal hastalık arasında pozitif bir ilişki olduğu söylenebilir. Bununla birlikte, stres ve periodontal hastalık arasındaki ilişkiyi açıklamak için daha ileri araştırmalara ihtiyaç vardır.

Anahtar Kelimeler: stres, periodontal hastalık, kortizol

\section{ABSTRACT}

Aim: Psychosocial factors are identified as an important risk factor for periodontal disease, affecting periodontal tissues by altering host resistance and endocrine imbalances. At present study, there was aimed to evaluate the relationship between perceived stress scale and stress hormone level and periodontal status.

Material and Methods: There was included the total of 72 individuals, 42 subjects with gingivitis and 30 periodontal healthy subjects in this study. Clinical and radiological periodontal evaluation of all participants were performed. Stress levels were assessed using salivary cortisol level and Cohen's Perceived Stress Scale (PSS-10) scores. Salivary cortisol level was measured using by ELISA method. The data were analyzed statistically according to $p<0.05$ significant levels.

Results: When the sociodemographic data were compared, no statistical difference was found between the groups $(p>0.05)$. Salivary cortisol level and PSS10 scores in periodontal healthy subjects were lower than subjects with gingivitis $(p<0.05)$. There was a positive correlation between salivary cortisol level and perceived stress scale scores and periodontal clinical parameters.

Conclusion: There were higher levels of stress in individuals with gingivitis. According to the present study might mention that there is a positive relationship between stress and periodontal disease. However, the further investigations are needed to explain the relationship between stress and periodontal disease.

Keywords: stress, periodontal disease, cortisol

\footnotetext{
${ }^{*}$ Abant İzzet Baysal Üniversitesi Diş Hekimliği Fakültesi, Periodontoloji AD, Bolu.

${ }^{* *}$ Necmettin Erbakan Üniversitesi Diş Hekimliği Fakültesi, Periodontoloji AD, Konya.
} 


\section{GİRİş}

Periodontal hastalığın hafif şekli olan gingivitis, ataşman kaybı olmaksızın dişeti inflamasyonuyla karakterize, geri dönüşümlü bir hastalık olarak tanımlanır. ${ }^{1}$ Yeterli plak retansiyonu ve birikimi olması halinde, mikrobiyal ürünler daha belirgin bir inflamatuvar yanıt oluşturur ve gingivitis tablosu kendini gösterir. ${ }^{2}$ Plakla indüklenen gingival durumlar, dental plak ve biyofilmde bulunan mikroorganizmalar ile konağın inflamatuvar hücreleri arasındaki etkileşimlerin bir sonucudur. Plak-konak etkileşimi lokal faktörlerden, sistemik hastalıklardan, ilaç kullanımından ve beslenmeden etkilenir. ${ }^{3}$

Birçok çalışma, periodontal durum ve psikososyal faktörler arasında pozitif bir ilişki olduğunu ortaya koymuştur. ${ }^{4}$ Johansen ve ark. kendi kendine bildirilen kaygının, gingival inflamasyonu olumsuz yönde etkilediğini göstermişlerdir. ${ }^{5}$ Uzun süreli strese maruz kalmanın hastalarda periodontal durumun kötüleşmesine katkıda bulunabiliceği rapor edilmiştir. ${ }^{6}$

Psikososyal stres bir bireyi ağız hijyeni uygulamalarının yetersizliği, aşırı derecede sigara içilmesi ve daha yağlı gıdaların tüketilmesi gibi yaşam kalitesindeki değişikliklerle dolaylı olarak ya da farklı biyokimyasal mekanizmalar ile doğrudan etkileyebilir. ${ }^{7}$ $\mathrm{Bu}$ ilişkide yer alan biyokimyasal mekanizmalar henüz aydınlatılamamış olsa da, hipotalamus-hipofiz-adrenal (HPA) eksenindeki psikososyal faktörle ilişkili değişikliklerin periodontal doku bozulmasına yol açarak bakteriyel kolonizasyonu kolaylaştıracağı ve proinflamatuvar ile anti-inflamatuvar yanıt arasındaki dengeyi bozabileceğini bildirilmiştir. ${ }^{8-10}$ Psikososyal stres durumunda HPA ekseni aktivasyonunu, ardından hipotalamustan kortikotropin salgılatıcı hormon sekresyonunu, hipofiz bezinden adrenokortikotropik hormonu (ACTH) ve adrenal korteksten glukokortikoidlerin salınımını içeren bir dizi olaylar gerçekleşir. HPA ekseninin uyarılmasından sonra, psikososyal faktörlere karşı vücut sıvılarındaki kortizol konsantrasyonunda artış gözlenir., ${ }^{911}$ Bağışıklık sisteminin işlevlerini etkileyen dolaşımdaki kortizolün artışı periodontal durumu etkiler. ${ }^{10}$ Genco ve ark., psikososyal stresörlerin, merkezi sinir sisteminin aktivasyonuna yol açan olaylar dizisinin başlatılmasında oynayabileceği potansiyel rolü gösteren şematik bir model önermiştir. ${ }^{9} \mathrm{Bu}$ modele göre, kortizol dahil olmak üzere glukokortikosteroidler, salgısal immünoglobulin A ve G (sIgA, sIgG) üretimini inhibe ederek bağışıklık yanıtını bastırır ve periodontal mikroorganizmaların neden olduğu enfeksiyona karşı savunmayı engelleyebilir. ${ }^{10}$ Moss ve ark., depresyon skorları ve 3 periodontal patojen (Tannerella forsythia, Porphyromonas gingivalis, Aggregatibacter actinomycetemcomitans) için antikor seviyeleri arasındaki etkileşimi değerlendirdikleri vaka kontrol çalışmasında, stresin bağışıklık fonksiyonunda rol oynadığını göstermişlerdir. ${ }^{12}$ Johannsen ve ark., plak miktarı farklılık göstermeyen kaygılı olan ve olmayan hastalardaki kaygı ve gingival inflamasyon arasındaki ilişkinin bağışıklık sisteminin bozulmasından kaynaklanabileceğini belirtmişlerdir. ${ }^{5}$

Kortizol adrenal korteks tarafından üretilen başlıca glukokortikoiddir. Kortizol, doğal öldürücü hücrelerin veya makrofajların fonksiyonunu baskılayarak ve $\mathrm{T}$ lenfositlerin formasyonunu inhibe ederek antiinflamatuvar ve immünsüpresif bir hormon olarak rol oynar. ${ }^{13}$ Kortizolün tükürük seviyesi HPA eksen aktivitesini güvenilir bir şekilde yansıtmaktadır ve biyolojik bir stres belirteci olarak pek çok çalışmada kullanılmıştır. ${ }^{14}$ Tükürük kortizolünün aynı zamanda periodontal hastalık şiddeti, yaygınlığı ve alveoler kemik kaybıyla ilişkili olduğu rapor edilmiştir. ${ }^{13} \mathrm{Bu}$ nedenle psikososyal stresin periodontal duruma etkisini inceleyen çalışmalarda tükürük kortizol seviyesiyle periodontal durum arasındaki ilişki araştırılmıştır. ${ }^{6,15,16}$ Çalışmaların çoğu periodontal hastalık ve psikososyal stres arasında pozitif bir ilişki olduğunu rapor ederken $^{8,10,16,17}$, aksi görüşü savunan çalışmalar da mevcuttur. ${ }^{18}$

Psikososyal stresin değerlendirilmesinde kullanılan bir diğer parametre de algılanan stres seviyesidir. Algılanan stres, yaşamı tehdit eden bazı olayların kişisel değerlendirmesidir ve bu algı kişinin yaşamındaki olaylarla başa çıkma yetisinin azlığı sonucu gözlenir. ${ }^{19,20}$ İnsanlar olası stresli yaşam olaylarını farklı değerlendirir. Algılanan stresli yaşam olaylarının sonucunda gözlenen stres algısını değerlendirmek için yaygın kullanılan ölçeklerden biri Cohen ve ark., tarafından 1988'de oluşturulan Algılanan Stres Ölçeği'dir (ASÖ-10). ${ }^{20}$ Algılanan Stres Ölçeği hamile olan ve olmayan kadınlarda, periodontal tedavinin gingival inflmasyon ve stres belirteçleri üzerine etkisinin değerlendirildiği çalışmalarda da kullanılmıştır. $^{21}$ Ölçekte değerlendirilen stres algısının tam ölçülebilmesi, planlanan tedavinin ve yapılan müdahalelerin etkinliğini arttırmak için oldukça önemlidir. 
Konak dokunun bağışıklığında değişikliğe neden olabilecek ve sağlık davranışlarını değiştirebilecek stres gibi faktörler daha fazla dikkate alınmalıdır. Gingivitis ve stres arasındaki ilişkiyi değerlendiren literatür sayısı çok kısıtlı olduğundan, bu konuda daha fazla araştırma yapılması bu hipotezin değerlendirilmesine katkıda bulunabilir. Bu nedenle, bu çalışmada, algılanan stresin ve strese bağlı hormon düzeyinin periodontal durum ile arasındaki ilişkisinin incelenmesi amaçlanmıştır.

\section{GEREÇ VE YÖNTEM}

Bu çalışma çeşitli periodontal problemlerden dolayı Bolu Abant İzzet Baysal Üniversitesi Diş Hekimliği Fakültesi Periodontoloji Anabilim Dalı́na başvuran 42 gingivitisli (21 kadın, 21 erkek) ve 30 periodontal sağlıklı (16 kadın, 14 erkek), toplam 72 birey ile yürütüldü. Çalışmaya dahil edilen tüm bireylere çalışmayla ilgili bilgilendirme yapılarak, aydınlatılmış onamları alındı. Ayrıca, çalışma protokolü Bolu Abant İzzet Baysal Üniversitesi Tıp Fakültesi Etik Kurulu tarafından onaylandı (2018/118).

Çalışmaya dahil edilen bireylerin; dental muayenelerinde 20'den daha az dişinin olmamasına, sigara kullanmamış olmasına, sistemik olarak sağlıklı olmasına, son 6 ay içinde herhangi bir periodontal tedavi almamış olmasına, periodontal durumu etkileyen herhangi bir ilaç kullanmamış olmasına, kadın hastaların gebe veya laktasyon döneminde olmamalarına dikkat edildi.

Çalışma grubu klinik ve radyolojik inceleme sonucunda, tüm bölgelerin $\geq \% 10$ unda sondalamada kanama gözlenen, sondalama cep derinliği $\leq 3 \mathrm{~mm}$ olan, klinik ataşman kaybı ve alveoler kemik kaybı gözlenmeyen bireylere gingivitis teşhisi konularak seçildi. Kontrol grubu ise klinik ve radyografik ataşman kaybı bulunmayan, sondalamada kanama olmayan, sondalama cep derinliği $\leq 3 \mathrm{~mm}$ olan bireyler periodontal olarak sağlıklı bireyler kabul edilerek çalışmaya dahil edildi. ${ }^{22}$

\section{Periodontal Değerlendirme}

Çalışmaya dahil edilen bireylerin periodontal klinik muayenesinde, tüm ağız plak indeksi $(P \dot{I})^{23}$, gingival indeksi $(\mathrm{GI})^{24}$, sondalama cep derinliği (SCD) ve sondalamada kanama indeksi (SKİ) ölçümleri kaydedildi. Periodontal klinik parametreler her dişin 6 noktasından Williams periodontal sondu kullanılarak, tükürük örneklerinin toplanmasını takiben gerçekleştirildi.

\section{Algılanan Stresin Düzeyinin Değerlendirilmesi}

Algılanan stres düzeyinin değerlendirilmesi için, Türkçe 'ye çevirisi yapılmış, güvenilirliği ve geçerliliği kanıtlanmış Cohen Algılanan Stres Ölçeği kullanıldı. ${ }^{25}$, ${ }^{26} 10$ sorudan oluşan bu ölçeğin puan değerlerine göre < 9 olması düşük stres düzeyine, 9-16 arasında olması orta derecede stres düzeyine, $16<$ olması da yüksek stres düzeyine işaret etmektedir. Ölçeğin puanlaması 0-40 arasında değişen değerlerdedir. ${ }^{27}$ Hastalara sakin bir ortamda, dilediği kadar süre tanındı ve ASÖ-10 anketi sorularına cevap vermeleri istendi.

Tükürük Örneklerinin Toplanması ve Değerlendirilmesi

Hastaların stimule olmayan tükürük örnekleri alınmadan 1 saat öncesinde hastalardan herhangi bir besin maddesi ve herhangi bir ilacı almamaları, ruj gibi kozmetikleri kullanmamaları, ağız bakımlarını bir gece önceden gerçekleştirmeleri istendi. Bireylerin stimule olmayan tükürük örneklerinin alımı sabah 09: 00 ile 11: 00 saatleri arasında, bireyler sakin bir şekilde iken oturur pozisyonunda bireylere verilen polipropilen eppendorf tüplerine tükürme metodu kullanılarak toplandı. Alınan örneklerden kanla kontamine olan örnekler çalışma dışı bırakılarak örnek alımı tekrarlandı. Eppendorf tüplerinde toplanan tükürük örnekleri $3.220 \mathrm{rpm}$ 'de $10 \mathrm{dk}$ santrifüj edilip, numaralandırılarak sporlara yerleştirildi ve $-20^{\circ} \mathrm{C}^{\prime} \mathrm{de}$ analiz gününe kadar muhafaza edildi. ${ }^{28}$ Toplanan tükürük örneklerindeki kortizol seviyesi üretici firmanın önerileri doğrultusunda ELİSA yöntemi ile belirlendi (Elabscience Biotechnology Co., Wuhan, Çin). Sonuçlar absorbans-konsantrasyon eğrisi çizilerek $\mathrm{ng} / \mathrm{mL}$ olarak hesapland.

\section{İstatistiksel Analiz}

Veriler, SPSS for Windows 15.0 (IBM SPSS Statistics 19, SPSS inc., an IBM Co., Somers, NY) paket programı ile değerlendirildi. KolmogorovSimirnov testi ile verilerin normal dağılım gösterip göstermediği belirlendi. Tüm veriler ortalama ve standart sapma olarak sunuldu. Gruplar arasındaki nitel değişkenler Ki-Kare testi, nicel değişkenler de T testi kullanılarak değerlendirildi. Klinik periodontal parametrelerle stres belirteçleri arasındaki ilişki Pearson Korelasyon Analizi ile yapıldı. İstatistiksel analizlerde $p<0.05$ değeri anlamlı kabul edildi. 


\section{BULGULAR}

Çalışmamıza 42 gingivitisli ve 30 periodontal olarak sağlıkı, toplam 72 birey dahil edildi. Gingivitisli grubun yaş ortalaması $27.33 \pm 6.09$, periodontal olarak sağıklı grubun yaş ortalaması $26.73 \pm 3.39$ olup, gruplar arası istatistiksel olarak anlamlı bir fark gözlenmedi. Çalışma dahil edilen bireylerin sosyodemografik verilerinin dağıımı Tablo 1'de görülmektedir.

Klinik periodontal parametreler değerlendirildiğinde gingivitisli grupta Pİ, Gİ, SCD ölçümlerinin istatistiksel olarak daha yüksek olduğu gözlendi (Tablo 2).

Gruplarda stres düzeyleri değerlendirildiğinde gingivitisli grupta istatistiksel olarak daha yüksek tükürük kortizol konsantrasyonu gözlendi. Algılanan stres ölçeği skorları sağlıklı grupta $8.70 \pm 2.68$, gingivitisli grupta ise $18.07 \pm 4.83$ olup, gingivitisli grupta istatistiksel olarak anlamlı bir farklılık vardı (Tablo 2).

Tükürük kortizol seviyesi ve algılanan stres ölçeği skorları ile periodontal klinik parametreler arasında pozitif korelasyon gözlendi (Tablo 3). Aynı zamanda stres belirteçleri arasında da pozitif bir korelasyon görüldü.

Tablo 1. Sosyodemografik verilerin dağıımı.

\begin{tabular}{|c|c|c|c|c|}
\hline & & $\begin{array}{l}\text { Periodontal } \\
\text { sağlıklı }\end{array}$ & Gingivitisli & $p$ \\
\hline \multirow[t]{2}{*}{$\begin{array}{l}\text { Yaş (Ortt } \pm \text { S.S) } \\
\text { Cinsiyet }(\mathrm{n}(\%))\end{array}$} & Kadın & $\begin{array}{c}26.7 \pm 3.39 \\
16(53.3)\end{array}$ & $\begin{array}{c}27.33 \pm 6.09 \\
21(50.0)\end{array}$ & 0.628 \\
\hline & Erkek & $14(46.7)$ & $21(50.0)$ & 0.780 \\
\hline $\begin{array}{l}\text { Eğitim Durumu } \\
(\mathrm{n}(\%))\end{array}$ & $\begin{array}{l}\text { İlkokul } \\
\text { Ortaokul } \\
\text { Lise } \\
\text { Üniversite }\end{array}$ & $\begin{array}{c}0(0.0) \\
4(13.3) \\
8(26.7) \\
18(60.0)\end{array}$ & $\begin{array}{c}7(16.7) \\
4(9.5) \\
7(16.7) \\
24(57.1)\end{array}$ & 0.107 \\
\hline $\begin{array}{l}\text { Sosyoekonomik } \\
\text { Durum (n (\%)) }\end{array}$ & $\begin{array}{l}1500 \mathrm{TL} \\
\text { altı } \\
1500- \\
2999 \mathrm{TL} \\
3000 \mathrm{TL} \\
\text { ve üzeri }\end{array}$ & $\begin{array}{c}7(23.3) \\
5(16.7) \\
18(60.0)\end{array}$ & $\begin{array}{l}9(21.4) \\
11(26.2) \\
22(52.4)\end{array}$ & 0.629 \\
\hline $\begin{array}{l}\text { Fırçalama } \\
\text { sıklığı (n (\%)) }\end{array}$ & $\begin{array}{l}\text { Günde } 1 \\
\text { kez } \\
\text { Günde } 2 \\
\text { kez } \\
\text { Diğerleri }\end{array}$ & $\begin{array}{c}0(0.0) \\
30(100) \\
0(0.0)\end{array}$ & $\begin{array}{l}18(42.9) \\
14(33.3) \\
10(23.8)\end{array}$ & $0.000^{*}$ \\
\hline
\end{tabular}

* Ístatistiksel olarak $p<0.05$ seviyesinde anlam/ılığı ifade etmektedir. Ort: ortalama; S.S: standart sapma
Tablo 2. Periodontal parametreler ile stres belirteçlerin ölçümleri

\begin{tabular}{|lccc|} 
& $\begin{array}{c}\text { Periodontal } \\
\text { sağlıklı }\end{array}$ & Gingivitisli & p \\
\cline { 2 - 3 } & Ort \pm S.S & Ort \pm S.S & \\
\cline { 2 - 3 } $\begin{array}{l}\text { Kortizol } \\
(\mathrm{ng} / \mathrm{mL})\end{array}$ & $0.86 \pm 0.31$ & $1.27 \pm 0.39$ & $\mathbf{0 . 0 0 0 *}$ \\
ASÖ-10 & $8.70 \pm 2.68$ & $18.07 \pm 4.83$ & $\mathbf{0 . 0 0 0 *}$ \\
$\mathbf{P I}$ & $0.45 \pm 0.37$ & $2.10 \pm 0.74$ & $\mathbf{0 . 0 0 0 *}$ \\
$\mathbf{~ G \dot { I }}$ & $0.20 \pm 0.24$ & $1.56 \pm 0.74$ & $\mathbf{0 . 0 0 0 *}$ \\
$\mathbf{S C D}(\mathrm{mm})$ & $2.19 \pm 0.33$ & $1.79 \pm 0.60$ & $\mathbf{0 . 0 0 1}$ \\
\hline
\end{tabular}

* İstatistiksel olarak p<0.05 seviyesinde anlam/ılığı ifade etmektedir. ASÖ-10: Algılanan stres ölçeği-10; PI: plak indeksi; GI; gingival indeks; SCD: sondalama cep derinliği

Tablo 3. Periodontal klinik parametreler ile stres belirteçleri arasındaki korelasyonlar

\begin{tabular}{|c|c|c|c|c|c|c|}
\hline \multirow[b]{2}{*}{ Kortizol } & & Kortizol & $S C D$ & $\boldsymbol{P} \dot{I}$ & $\boldsymbol{G \dot { I }}$ & $\begin{array}{r}A S O ̈ \\
10\end{array}$ \\
\hline & $\begin{array}{l}r \\
p\end{array}$ & 1 & & & & \\
\hline \multirow[t]{2}{*}{$S C D$} & $r$ & .168 & & & & \\
\hline & P & .159 & & & & \\
\hline \multirow[t]{2}{*}{$\boldsymbol{P} \dot{I}$} & $r$ & .397 & .412 & & & \\
\hline & P & $.001^{*}$ & $.000^{*}$ & 1 & & \\
\hline \multirow[t]{2}{*}{$\boldsymbol{G} \dot{\boldsymbol{I}}$} & $r$ & .257 & .411 & .810 & & \\
\hline & P & $.030^{*}$ & $.000^{*}$ & $.000^{*}$ & 1 & \\
\hline \multirow[t]{2}{*}{ ASÖ-10 } & $r$ & .476 & .237 & .588 & .569 & \\
\hline & $\mathrm{P}$ & $.000^{*}$ & $.045^{*}$ & $.000^{*}$ & $.000^{*}$ & 1 \\
\hline
\end{tabular}

* Ístatistiksel olarak p<0.05 seviyesinde anlamlılı̆ı ifade etmektedir. ASÖ-10: Algılanan stres ölçeği-10; Pİ: plak indeksi; Gí: gingival indeks; SCD: sondalama cep derinliği

\section{TARTIŞMA}

Günümüzde, periodontal hastalıkların fizyopatolojisi ve etiyopatolojisine yönelik çalışmalar yerini, periodontal hastalıkların patogenezinde rol oynayan mekanizmaların anlaşılmasına bırakmıştır. ${ }^{29}$ Stres, anksiyete ve depresyon gibi psikososyal faktörler periodontal hastalık için bir risk faktörü olabileceğinden, stres ve periodontal durum arasındaki ilişkiyi inceleyen çalışmalar bu açıdan dikkat çekicidir. Psikososyal faktörler ile periodontal hastalık arasındaki ilişki başlıca iki mekanizma ile açıklanmaktadır. Strese bağlı olarak HPA eksen aktivasyonu sonucu immün sistemde

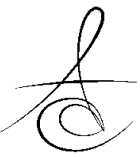


oluşan baskılanma ve ağız hijyeni alış- kanlıkları ile sigara kullanımı gibi davranışsal faktörler- deki olumsuz değişimlerin periodonsiyumu etkilemesi söz konusu mekanizmalardır. ${ }^{30}$ HPA ekseninin aktivasyonu ile adrenal korteksten salgılanan en önemli glukokortikoid olan kortizolün inflamatuvar cevap ve immün sistem üzerinde meydana getirdiği değişikliklerden yola çıkılarak, literatürde pek çok çalışmada stres ve periodontal hastalık arasındaki ilişkiyi açıklamak için kortizol seviyeleri incelenmiştir. ${ }^{31-34}$

Hilgert ve ark., tarafından 50 yaş üstü bir popülasyonda stres semptomları skorlarının, kortizol seviyeleriyle ve kronik periodontitisin şiddetiyle ilişkisi değerlendirilmiştir. Sonuçlar periodontal hastalık şiddeti, yaygınlığı ile kortizol seviyeleri arasında pozitif bir ilişki olduğunu göstermektedir. ${ }^{35}$ Stresle periodontal hastalık arasındaki ilişkiyi inceleyen diğer bir çalışmada ise yetişkin bireylerde gingivitis varlığının artışına psikososyal faktörlerin katkısı olduğu ve plak birikiminin stresle arttığı rapor edilmiştir. ${ }^{36,37}$ Stresle ilişkili depresyon teşhisi konulan kadınları ve sağlıklı kontrolleri ele alan karşılaştırmalı çalışmada, deprese bireylerde kortizol seviyesinin daha yüksek olduğu ve daha yüksek gingivitis insidansının olduğu rapor edilmiştir. ${ }^{38}$ Depresyon, stres ve tükürük kortizolünün dental hijyenden bağımsız olarak, periodontal hastalık değişkenleriyle ilişkili olduğu sonucuna varılmıştır. Benzer bir çalışmada da serum kortizol konsantrasyonunun cep derinliği, klinik ataşman seviyesi ve sondalamada kanama gibi klinik periodontal parametrelerle ilişkili olduğu rapor edilmiştir. ${ }^{39} \mathrm{Bu}$ bulgularla paralel olarak çalışmamızda da periodontal sağlıklı bireylere kıyasla gingivitisli bireylerde daha yüksek tükürük kortizol seviyesi gözlenmektedir.

Stresin objektif ölçümü kadar subjektif ölçümü de önemlidir ve algılan stres düzeyinin yüksek olması bir bireyi periodontal hastalığa yatkın hale getirebilir. ${ }^{8,22}$ Çeşitli çalışmalarda algılanan stres düzeyinin belirlenmesiyle tedavi etkinliğinin arttırabileceği belirtilmiştir. ${ }^{26,}$ 40-41 Bundan dolayı, stresin, stres ile periodontal hastalık arasındaki ilişkinin değerlendirilmesi önemlidir. ${ }^{41}$ Johanssen ve ark., algılanan akademik stresi görsel analog skala ile değerlendirdikleri bir çalışmada, kortizol ve algılanan stres düzeyi arasında pozitif bir ilişkiyi belirtmişlerdir. ${ }^{42}$ Çalışmamızda stres belirteci olarak bilinen bir hormon olan kortizolün yanı sıra algılan stresin ölçülmesinde kullanılan ASÖ-10

ölçeği ile periodontal durum arasındaki ilişki değerlendirildi ve gruplar arasındaki stres algısının gingivitisli bireylerde daha yüksek olduğunu ve periodontal klinik parametrelerle algılanan stres arasında pozitif korelasyon olduğu gözlemlendi. Çalışmamızın bulguları doğrultusunda periodontal hastalığı bulunan bireylerde hem objektif hem de subjektif stres seviyesinin daha yüksek olduğu söylenebilir.

$\mathrm{Bu}$ çalışmada gingivitisli bireyler ile sağlıklı kontroller karşılaştırılarak, daha homojen bir grupta stres ve periodontal durum arasındaki ilişkisinin değerlendirilmesi amaçlanmıştır. Ancak çalışmanın bazı limitasyonları vardır. Periodontitisli hastaların çalışmaya dahil edilmemiş olması çalışmanın limitasyonlarındandır. Kötü ağız hijyeni gingivitiste beklenen bir durumdur. Gingivitisli hastaların sağlıklı kontroller ile kıyaslanması, kötü ağız hijyeninin çalışmanın sonuçlarını olumsuz etkilemesi çalışmanın diğer bir limitasyonudur. Çalışma sonuçlarının daha güçlü, güvenilir ve genellenebilir olabilmesi için birey sayısının daha fazla olduğu, farklı periodontal hastalığa sahip bireylerin de çalışmaya dahil edildiği ve periodontal tedavi sonrası stres seviyelerindeki değişimin değerlendirildiği çalışmalara intiyaç vardır.

\section{SONUÇ}

Gingivitisli bireylerde daha yüksek stres seviyesi olduğu görülmüştür. Çalışmamızın sonuçları dahilinde stres ile periodontal hastalık arasında pozitif bir ilişki olduğu söylenebilir. Bununla birlikte, stres ve periodontal hastalık arasındaki ilişkiyi açıklamak için daha ileri araştırmalara intiyaç vardır.

Özge Göktürk: ORCID ID: 0000-0002-3147-735X

Fatma Uçan Yarkaç: ORCID ID: 0000-0001-8126-585X

Ferhat Özelçi:ORCID ID: 0000-0001-8485-0288

\section{KAYNAKLAR}

1. Pihlstrom BL, Michalowicz BS, Johnson NW. Periodontal diseases. The Lancet 2005;366:180920.

2. Leininger $M$, Tenenbaum $H$, Davideau JL. Modified periodontal risk assessment score: long-term predictive value of treatment outcomes. A retrospective study. J Clin Periodontol 2010; 37:427-35. 
3. Murakami S, Mealey BL, Mariotti A, Chapple IL. Dental plaque-induced gingival conditions. . J Clin Periodontol 2018;45:17-27.

4. Peruzzo DC, Benatti BB, Ambrosano GM, NogueiraFilho GR, Sallum EA, Casati MZ, et al. A systematic review of stress and psychological factors as possible risk factors for periodontal disease. ] Periodontol 2007;78:1491-1504.

5. Johannsen A, Åsberg M, Söder PÖ, Söder B. Anxiety, gingival inflammation and periodontal disease in non-smokers and smokers-an epidemiological study. J Periodontol 2005;32:48891.

6. Johannsen A, Rydmark I, Soder B, Asberg M. Gingival inflammation, increased periodontal pocket depth and elevated interleukin- 6 in gingival crevicular fluid of depressed women on long-term sick leave. J Periodontal Res 2007;42:546-52.

7. LeResche $L$, Dworkin SF. The role of stress in inflammatory disease, including periodontal disease: review of concepts and current findings. Periodontol 2000 2002;30:91-103.

8. Peruzzo DC, Benatti BB, Ambrosano GM, , Nogueira-Filho GR, Sallum EA, Casati MZ, et al. A systematic review of stress and psychological factors as possible risk factors for periodontal disease. J Periodontol 2007;78:1491-504.

9. Genco RJ, Ho AW, Kopman J, Grossi SG, Dunford RG, Tedesco LA. Models to evaluate the role of stress in periodontal disease. Ann Periodontol 1998;3:288-302.

10. Sheiham A, Nicolau B. Evaluation of social and psychological factors in periodontal disease. Periodontol 2000 2005;39:118-31.

11. Axtelius B, Söderfeldt B, Nilsson A, Edwardsson S, Attström R. Therapy-resistant periodontitis. Psychosocial characteristics. J Clin Periodontol 1998;25:482-91.

12. Moss ME, Beck JD, Kaplan BH, Offenbacher S, Weintraub JA, Koch GG, et al. Exploratory casecontrol analysis of psychosocial factors and adult periodontitis. J Periodontol 1996;67:1060-9.

13. Kiecolt-Glaser JK, Preacher KJ, MacCallum RC, Atkinson C, Malarkey WB, Glaser R. Chronic stress and age-related increases in the proinflammatory cytokine IL-6. Proc Natl Acad Sci USA 2003; 100: 9090-5.
14. Groer M, Murphy R, Bunnell W, Salomon K, Van Eepoel J, Rankin B, et al. Salivary measures of stress and immunity in police officers engaged in simulated critical incident scenarios. J Occup Environ Med 2010;52:595-602.

15. Jentsch $H$, März D, Krüger $M$. The effects of stress hormones on growth of selected periodontitis related bacteria. Anaerobe 2013;24:49-54.

16. Rosania AE, Low KG, McCormick CM, Rosania DA. Stress, depression, cortisol, and periodontal disease. J Periodontol 2009;80:260-266.

17. Hilgert J, Hugo F, Bandeira D, Bozzetti M. Stress, cortisol, and periodontitis in a population aged 50 years and over. J Dent Res 2006;85:324-8.

18. Mengel $R$, Bacher $M$, Flores-de-Jacoby $L$. Interactions between stress, interleukin-1 $\beta$, interleukin- 6 and cortisol in periodontally diseased patients. J Clin Periodontol 2002;29:1012-22.

19. Lazarus RS. Psychological stress and the coping process. New York, NY, US, 1966.

20. Cohen S. The Social Psychology of Health, Sage, Newbury Park, CA, 1988, 31-67.

21. Yarkac FU, Gokturk O, Demir O. Effect of nonsurgical periodontal therapy on the degree of gingival inflammation and stress markers related to pregnancy. J Appl Oral Sci 2018;26.

22. Chapple IL, Mealey BL, Van Dyke TE, Bartold PM, Dommisch $\mathrm{H}$, Eickholz $\mathrm{P}$, et al. Periodontal health and gingival diseases and conditions on an intact and a reduced periodontium: Consensus report of workgroup 1 of the 2017 World Workshop on the Classification of Periodontal and Peri-Implant Diseases and Conditions. J Clin Periodontol 2018;45:68-77.

23. Silness J, Löe H. Periodontal disease in pregnancy II. Correlation between oral hygiene and periodontal condition. Acta Odontol Scand 1964;22:121-35.

24. Löe $H$. The gingival index, the plaque index and the retention index systems. J Periodontol 1967;38:610-6.

25. Eskin M, Harlak H, Demirkıran F, Dereboy Ç. Algılanan Stres Ölçeğinin Türkçeye Uyarlanması: Güvenirlik ve Geçerlik Analizi. In: New Symposium Journal 2013;51:132-40.

26. Cohen S, Kamarck T, Mermelstein R. A global measure of perceived stress. J Health Soc Behav 1983:385-96. 
27. Redmond N, Richman J, Gamboa CM, Albert MA, Sims M, Durant RW, et al. Perceived stress is associated with incident coronary heart disease and all-cause mortality in low-but not high-income participants in the Reasons for Geographic And Racial Differences in Stroke study. J Am Heart Assoc 2013;2:e000447.

28. Haririan H, Bertl K, Laky M, Rausch WD, Böttcher $M$, Matejka $M$, et al. Salivary and serum chromogranin $\mathrm{A}$ and a-amylase in periodontal health and disease. J Periodontol 2012;83:131421.

29. Cakmak O, Alkan BA, Ozsoy S, Sen A, Abdulrezzak $U$. Association of gingival crevicular fluid cortisol/dehydroepiandrosterone levels with periodontal status. J Periodontol. 2014;85:287-94.

30. Sheiham A, Nicolau B. Evaluation of social and psychological factors in periodontal disease. Periodontol 2000 2005;39:118-31.

31. Goyal S, Jajoo S, Nagappa G, Rao G. Estimation of relationship between psychosocial stress and periodontal status using serum cortisol level: a clinico-biochemical study. Indian J Dent Res 2011;22:6-9.

32. Ishisaka A, Ansai T, Soh I, Inenaga K, Awano S, Yoshida $A$, et al. Association of cortisol and dehydroepiandrosterone sulphate levels in serum with periodontal status in older Japanese adults. J Clin Periodontol 2008;35:853-61.

33. Johannsen A, Rylander G, Soder B, Asberg M. Dental plaque, gingival inflammation, and elevated levels of interleukin- 6 and cortisol in gingival crevicular fluid from women with stress-related depression and exhaustion. J Periodontol 2006;77:1403-9.

34. Refulio Z, Rocafuerte M, de la Rosa M, Mendoza G, Chambrone L. Association among stress, salivary cortisol levels, and chronic periodontitis. J Periodontal Implant Sci 2013;43:96-100.

35. Hilgert JB, Hugo FN, Bandeira DR, Bozzetti MC. Stress, cortisol, and periodontitis in a population aged 50 years and over. J Dent Res 2006;85:3248.

36. Deinzer R, Schüller N. Dynamics of stress-related decrease of salivary immunoglobulin $A(\operatorname{sgA})$ : relationship to symptoms of the common cold and studying behavior. Behav Med 1998;23:161-9.
37. Deinzer R, Hilpert D, Bach K, Schawacht M, Herforth A. Effects of academic stress on oral hygiene-a potential link between stress and plaque-associated disease? J Clin Periodontol 2001;28:459-64.

38. Johannsen A, Rylander G, Söder B, Marie A. Dental plaque, gingival inflammation, and elevated levels of interleukin-6 and cortisol in gingival crevicular fluid from women with stress-related depression and exhaustion. J Periodontol 2006;77:1403-9.

39. Saxby MS. Destructive forms of periodontal disease in adolescents and young adults. $\mathrm{Br}$ Dent J 1985; 159:206.

40. Sudhanshu A, Sharma U, Vadiraja H, Rana RK, Singhal R. Impact of yoga on periodontal disease and stress management. Int J Yoga 2017;10:121.

41. Fenol A, Jebi S, Krishnan S, Perayil J, Vyloppillil R, Bhaskar A, et al. Association of stress, salivary cortisol level, and periodontitis among the inmates of a central prison in Kerala. Dent Res J 2017; 14:288.

42. Johannsen A, Bjurshammar N, Gustafsson A. The influence of academic stress on gingival inflammation. Int J Dent Hyg 2010;8:22-7.

\author{
Yazışma Adresi \\ Fatma UÇAN YARKAÇ \\ Necmettin Erbakan Üniversitesi \\ Diş Hekimliği Fakültesi \\ Periodontoloji AD \\ Konya 42050, Türkiye \\ Tel: 00903322200026 \\ E-mail: fatma ucan413@hotmail.com
}

